\title{
LANSKAP SIBER SASTRA: POSMODERNISME, SASTRA POPULER, DAN INTERAKTIVITAS
}

\author{
Sri Nurhidayah ${ }^{1}$, Rahmat Setiawan ${ }^{2}$ \\ STKIP Bina Insan Mandiri Surabaya1, Universitas PGRI Adi Buana Surabaya² \\ nurhidayah@stkipbim.ac.id ${ }^{1}$, wawan.rstw@gmail.com²
}

\begin{abstract}
Abstrak
Kajian ini bertujuan mengungkapkan kaitan antara posmodernisme, sastra populer, dan siber sastra. Dengan pemahaman posmodernisme sebagai pergerakan budaya, sastra populer sebagai sastra pelarian, dan siber sastra sebagai konsekuensi atas pergeseran produksi sastra yang memanfaatkan internet, kajian ini merelevansikan asumsi bahwa ketiganya memiliki kaitan yang cukup erat. Pendekatan kajian ini adalah fenomenologis dengan teknik analisis deskriptif. Posmodernisme menghasilkan pergeseran pola pikir terpusat menjadi tersebar sehingga batas antara yang adiluhung dengan yang populer menjadi kabur ditambah lagi dengan fenomena media sosial yang menghadirkan interaktivitas penulis-pembaca sebagai pola baru kesusastraan, seperti pemanfaatan media sosial (facebook, twitter, wattpad, dan lain sebagainya) yang mampu menawarkan intimasi antara penulis dengan pembaca serta bagaimana wacana kebebasan menulis menjadi hal yang realistis lagi tanpa perlu kompetisi ketat yang penuh dengan kekuasaan dan legitimasi. Tentu saja, interaktivitas penulis-pembaca tersebut merupakan hal yang sulit terwujud dalam produksi sastra yang konvensional (versi cetak).
\end{abstract}

Kata kunci: Posmodernisme, sastra popular, siber sastra, interaktivitas

\begin{abstract}
This study aims to reveal the relation among postmodernism, pop literature, and cyber literature. By the understanding of postmodernism as a cultural movement, popular literature as escape literature, and cyber literature as a consequence of the shift in literary production that utilizes the internet technology, this study revives an assumption that the three have a fairly close relationship. The approach of this study is phenomenological with descriptive analysis techniques. Postmodernism results in a shift in decentralization process, so that the margin between the noble and the popular get blurred along with the phenomenon of social media that faces writer-reader interactivity as a new mode of literature, such as the use of social media (facebook, twitter, wattpad, etc.). Those offer intimacy between writers and readers, as well as how the discourse of freedom of writing becomes realistic without requirement toward intense competition that is full of power and legitimacy. Of course, the writer-reader interactivity is difficult to be realized in conventional literary production (print version).
\end{abstract}

Keywords: Postmodernism, pop literature, cyber literature, interactivity

\section{Pendahuluan}

Posmodernisme menyiratkan diseminasi budaya serta paradigma tentang keterpusa- tan, termasuk bagaimana sastra mendefinisikan serta mengklasifikasi diri. Posmodern juga secara tidak langsung mendekonstruksi kesta- 
bilan klasifikasi antara sastra adiluhung dan sastra populer. Proses dinamika pemisah antara adiluhung dan populer menjadi semakin berantakan ketika kritik dekonstruktif yang khas dengan eksklusivitas sastra adiluhung justru mendestruksikan diri dan menjadi hal yang populer, seperti karya fiksi bertema LGBT, (a)moralitas, anti-hero, dan lain sebagainya yang justru diterima publik dan menjadi populer. Ada peran perkembangan teknologi yang menjadikan fenomena nilai kesusastraan menyebar, bukan terpusat pada institusi representatif, melainkan berada pada kedekatan pembaca-penulis yang termediasi oleh media elektronik. Dari sini, siber sastra hadir. Artinya, siber sastra menciptakan interaktivitas pembaca-penulis.

Interaktivitas pembaca-penulis adalah mode baru dalam apresiasi sastra. Masyarakat siber berperan penting dalam menghadirkan fenomena interaktivitas karena mereka adalah pengguna aktif di jejaring maya atau media sosial. Media sosial memberikan ruang interaksi antara penulis dan pembaca, seperti halnya di twitter, facebook, wattpad, dan berbagai media sosial. Tiap aplikasi tersebut memiliki kelebihan, misalnya ada kolom komentar, fitur follow, thread, dan lain sebagainya. Misalnya saja, kolom komentar. Ia mampu memberikan ruang reaktif-baik itu ujaran kebencian maupun kekaguman, mulai kritik sampai apresiasi-pada pembaca sehingga interaksi terjadi. Interaktivitas penulis dan pembaca menghasilkan pertukaran pendapat.

Tentu saja, penyebaran karya sastra berkembang dari mode konvensional menuju mode kekinian, mulai dari koran, majalah, bu$\mathrm{ku}$, sampai pada media internet. Jika sastra terlahir secara prematur dalam lingkup sastra lisan kemudian bergerak menuju media cetak atau tulisan, yang akhirnya terjebak pada kendala finansial sampai kritik politis ekokritik yang menghambat penyebaran sastra melalui media cetak, nampaknya kehadiran sastra di dunia maya menjadi jalan perkembangan yang melampaui aktivitas konvensional sebelumnya. Jika dalam mode luar jaringan, penulis awam tidak memiliki peluang, dunia siber memberi peluang menulis di jejaring media sosial dengan akomodasi internet. Mulai dari koputer, laptop, tablet, sampai telepon genggam, internet adalah pemicu dari perangkat elektronik tersebut dan internet menjadikan informasi sebagai kebutuhan. Tentu saja, karya sastra dapat menyusup ke dalam perkembangan budaya dan teknologi tersebut. Menurut Ryan (2013), komputer tidak hanya menyediakan saluran transmisi untuk teks-teks fiksi penggemar, tetapi juga dapat menjadi alat produksi. Dari sini, dunia maya atau siber, telah menjadi fenomena lahirnya siberteks.

Sekali lagi, aplikasi media sosial seperti WhatsApp, Blogspot, Wattpad, Line, Facebook, Myspace, dan berbagai lainnya telah memberikan ruang responsif dan reaktif pembaca yang secara tidak langsung menjadi kontrol dan berkontribusi terhadap produksi karya sastra. Tentu saja, resepsi sastra menjadi kajian teoretis dan pendekatan yang cukup relevan dengan fenomena ini. Teori resepsi menekankan perhatian dari penulis dan karya ke teks dan pembaca. Reaksi pembaca pada proses pemaknaannya adalah siklus yang nant- 
inya berdampak pada perkembangan literasi secara sosial karena pembaca terikat dalam interaksi, bukan sosok eksternal dalam produksi sastra.

Ada tiga hal yang akan dibahas dalam tulisan ini. Pertama adalah pemahaman tentang posmodern. Kedua adalah sastra populer dan kaitannya dengan posmodern. Ketiga adalah pemahaman tentang dunia siber dan Internet yang berkaitan dengan perkembangan dunia kesusastraan.

\section{Posmodern(isme/itas)}

Istilah postmodern telah membumi di kalangan masyarakat saat ini. Istilah ini hampir menggerayangi seluruh bidang, mulai dari musik (seperti Cage), seni rupa (seperti Rauschenberg), arsitektur (seperti Jencks), fotografi (seperti Sherman), antropologi (seperti Clifford), sosiologi (seperti Denzin), filsafat (seperti Lyotard), drama (seperti Artaud), kritik sastra (seperti Spanos), film (seperti Lynch), fiksi (Vonnegut), dan lainlain.

Untuk memahami istilah posmodern, baiknya dikaitkan dengan istilah yang lazimnya digunakan, (pos)modernisme dan (pos)modernitas. Terlebih, istilah ini sulit untuk diistilahkan secara pasti karena tergantung dari bidang mana istilah ini dibuat. Kedua istilah ini sebenarnya cukup berbeda, posmodernisme cenderung bersifat filosofis, ideologis, dan memberi kesan jika ini suatu sistem pemikiran tunggal padahal di dalamnya banyak sekali cabang-cabang dari posmodernisme. Adapun istilah posmodernitas cenderung mengarah pada keadaan atau situasi masyarakat yang menanggapi (reaksi) konsekuensi-konsekuensi

modernitas (Sugiharto, 1996: 24).

Dimulai dari modernitas, istilah ini secara langsung terhubung pada zaman Renaissance, yaitu ketika rasionalitas berkembang, sehingga menyebabkan kemajuan. Renaissance menandai lahirnya filsafat politik (Machiavelli), kemajuan teknologi, mesin cetak (Coster), studi klasik, ilmu melukis (Leonardo da Vinci), ilmu kimia (Paracelsus), reformasi (Luther dan Calvin), astronomi (Copernicus), petualang (Vasco da Gama), dan lain sebagainya (Sarup, 2011: 202; Osborne, 1991: 58-59). Rasionalitas sendiri, bagi Descartes, memusatkan kebenaran melalui kesangsian-kesangsian, dan menyaringnya melalui pemikiran sampai hal yang sangsi itu benar-benar dapat diterima, atau rasional (Descartes, 1998: 18-19; Osborne, 1991: 74).

Bagi Webber, Tonnies, dan Simmel, modernitas juga dipahami sebagai proses-proses yang melahirkan negara industri kapitalis modern sehingga mencakup rangkaian sistem sosial, ekonomi, dan politik (Sarup, 2011: 202). Adapun tahap-tahapnya dinamakan modernisasi, yang meliputi pelbagai perubahan seperti inovasi ilmu dan pengetahuan, teknologi, industri, sosial, politik, dan ekonomi (Sarup, 2011: 202) sehingga modernisme dapat dikatakan sebagai paham atau gerakan kebudayaan yang mengacu pada orientasi modern. Kata kunci untuk menyingkat ini adalah rasionalitas Cartesian dan materialisme (kapitalisme) Marxis (Sugiharto, 1996: 26).

Era Renaissance-atau yang biasa disebut era pencerahan (enlightenment) - ternyata tid- 
ak seluruhnya berdampak positif, walaupun pada dasarnya era itu ditujukan untuk menjadikan kehidupan manusia lebih baik. Setidaknya, ada enam poin utama dari konsekuensi negatif dari era ini; (1) pandangan dualistik yang akhirnya berujung kerusakan ekologi, (2) pandangan objektivistis dan positivistis yang cenderung menjadikan manusia objek dan masyarakat menjadi mesin, (3) pandangan ilmu modern yang mendegradasikan orientasi moral dan agama, (4) pandangan materialisme yang menghapus nilai-nilai kemanusiaan, (5) militerisme yang merupakan dampak dari kekhawatiran terhadap persaingan serta hilangnya moral yang mengharuskan kekerasan sebagai jalan terbaik, (6) tribalisme yang menciptakan manusia yang terlalu komunal atau mementingkan kelompok sendiri (Sugiharto, 1996: 30).

Dari semua dampak penting tersebut, muncul orang-orang yang mengkritisi yang terbagi menjadi tiga kelompok, yaitu kelompok metafisika New Age yang ingin kembali pada pola pra-modern, kelompok dekonstruktionis yang bertolak dari bahasa sebagai struktur pembentuk manusia, dan kelompok yang hendak merevisi modernisme dengan masih menggunakan modernisme sebagai landasan dan mengurangi konsekuensi negatif daripadanya (Sugiharto, 1996: 3234). Orang-orang inilah yang dapat mungkin dapat dikatakan sebagai para posmodernis.

Posmodernitas, secara singkat, adalah apa yang muncul setelah modernitas dan ini dikaitkan dengan bobroknya segala bentuk yang terasosiasi dengan modernitas. Sifatsifat modernitas yang totalitas dan objektif didobrak dan diganti dengan identitas individu yang bersifat berbeda atau plural. Oleh karena itu, pluralisme yang dimaksudkan adalah, bentuk dari berakhirnya modernisme tentang subjek atau fundalisme (di sini fondasi adalah ilmu pengetahuan) dan objek atau representasionalisme (mempresentasikan objek).

Mendefinisikan artian posmodern(isme) cukup sulit karena istilah ini terlalu berantakan untuk dikerucutkan, misalnya Daniel Bell mengartikan posmodernisme sebagai berkembangnya kecenderungan yang saling bertolak belakang, Frederic Jameson menggunakan istilah posmodernisme sebagai logika kultural yang membawa transformasi (perubahan) dalam budaya umum, sedangkan Jean Baudrillard menandai modernitas sebagi ledakan dalam diri atau peleburan segala batas-batas dari oposisi biner. Dari semua pendapat itu, dapat dirumuskan jika semuanya mengacu pada apa yang terjadi sesudah atau dari (akibat) modernitas. Jika menilik dari unsur pos-, pernyataan akhir atau setelah dapat menjadi jelas. Namun, hal yang cukup ambigu dilontarkan Lyotard, " $a$ work can become modern only if it is first postmodern. Postmodernism thus understood is not modernism at its end but in the nascent state, and this state is constant." (Suatu karya hanya dapat menjadi modern jika pertama-tama ia adalah posmodern. Posmodernisme yang dipahami secara demikian menjadikan modernisme bukan pada tahap akhirnya, melainkan pada taraf kelahirannya, dan keadaan semacam ini adalah sesutau yang konstan) (Lyotard, 1984: 79). Jadi, apa yang dinamakan posmodernisme-bagi Lyotard-adalah intensifikasi dinamisme, upaya untuk selalu menemukan bentuk 
baru, eksperimen, dan revolusi yang tiada henti. Terlebih Lyotard menambahkan jika Posmodernisme adalah "...undoubtedly a part of the modern." (bagian dari modern) (Lyotard, 1984: 79).

Istilah posmodernisme sendiri muncul pertama kali di wilayah seni dan kritikus di New York pada 1960 (Sarup, 2011: 205; Lane, 2000: 103). Menurut Hasan dan Jencks, seperti yang dikutip Suguharto, istilah postmodern muncul pertama kali dalam karya "Antologia de la Poesia Espanola a Hispanoamericana" milik Federico de Onis di tahun 1930-an. Dari seni, terwakilkan peleburan batas-batas dari seni dan kehidupan sehari-hari, budaya popular dan elit. Dari hal itu, dapat dikelompokkan tiga kecenderungan-kecenderungan

yang beroperasi dalam bendera posmodernisme, seperti yang dikatakan oleh Callinicos, "Postmodern art (including literature, architecture, cinema), post-structuralist philosophy, and theories of postmodernity/ postindustrial society." (Seni posmodern (termasuk sastra, arsitektur, perfilman), filsafat pascastrukturalisme, dan teori-teori posmodernitas/masyarakat posinsdusrial) (Callinicos, 1989: 2-3).

Dari berbagai macam penjelasan serta definisi, dapat disimpulkan jika posmodern (isme/itas) jika istilah ini mengacu pada bentuk kritik atas gagalnya modern(isme/itas) dalam memenuhi janji-janji kemajuan mereka. Narasi ini, menentukan apa yang boleh dikatakan dan apa yang tidak boleh dikatakan dalam kebudayaan sehingga kuasa narasi dari modern(isme/itas) pada akhirnya harus berhadapan dengan apa yang sudah mereka buat. Manusia sebagai aktor dalam kebudayaan tersebut, menjalani peran atas terciptanya sebuah karya, dan jika terhubung dengan sastra popular, maka posmodern(isme/itas), sebagai gerakan kebudayaan, juga tak luput untuk berkontribusi terhadap kekacauan struktur hirarkis kebudayaan dan seni, termasuk klasifikasi sastra adiluhung dan populis.

\section{Sastra Populer}

Dengan membicarakan kaitan sastra popular dengan postmodernisme (teori), perlu dicari sebuah benang merah dari kusutnya istilah-istilah ini. Meningkatnya kemampuan masyarakat akibat terkomputerisasi, perbedaan narasi dan pengetahuan ilmiah (Sarup, 2011: 206), serta melek-nya masyarakat terhadap informasi dan teknologi, seakan-akan sedang mengonstruksi sebuah bangunan baru dalam budaya mereka. Budaya yang tidak hanya beralih, tapi budaya yang semakin meningkat dalam taraf kreativitas.

Peralihan ini, mau tak mau membuat dunia sastra, terlebih dunia sastra populer, juga mengikuti arus masyarakat yang posmodern tersebut. Jika dalam sastra adiluhung-sudah dimunculkan sedari dulu seperti dari cerpen Quality karya John Galsworthy tentang kritik budaya produksi dari modernitas, The Stranger karya Albert Camus dengan tokoh dengan absurditasnya, hingga pemenang fiksi pulitzer 2010, The Road karya Cormac McCarthy dengan kritik ekologi-dalam sastra populer ini dapat dilihat dari membeludaknya karya-karya yang diproduksi seperti Life of Pi karya Yann Martel. Novel ini menjadi pemenang The Man Booker 
Prize untuk kategori fiksi pada tahun 2002, dengan cerita yang sulit dipercaya dan hampir tak masuk akal, novel ini kemudian dicetak ulang pada medio 2010 sampai 2012 dengan tingkat penjualan mencapai hampir 10 juta kopi, terlebih, novel ini difilmkan pada tahun 2012 dengan penghasilan yang dapat diraup lebih dari $\$ 609$ juta.

Menilik dari itu, walaupun isi sulit diterima, tetapi tingkat pemahaman masyarakat meningkat, dapat dikatakan karya posmodern yang berbeda dengan karya modern tetap mampu masuk di kalangan masyarakat populer. Di segmen anak-anak dan remaja, produksi film-film animasi yang berbeda dengan animasi-animasi terdahulu (semacam Cinderella, Aladdin, dan lain sebagainya) menampilkan tokoh berkarakter baik yang selalu baik dan menang. Film-film animasi sekarang cenderung agak aneh, seperti film animasi Megamind dengan tokoh jahat yang tidak jahat, ParaNorman dengan tokoh aneh yang jadi pahlawan, Brave dengan tokoh putri (princess) yang tidak seperti putri pada umumnya, sampai Wreck-itRalph dengan tokoh antagonis (bagi tokohtokoh dalam cerita) yang sangat baik. Ini dapat dikatakan sebagai salah satu jenis karya posmodern karena meleburnya nilai-nilai yang total, meleburnya batasan-batasan ke"norma"-litasan, sehingga walaupun terlihat absurd, aneh, nyeleneh, tapi mereka laku karena pemikiran masyarakat yang juga posmo. Artinya, ada konektivitas antara hasrat skizofrenik masyarakat dengan produksi karya sastra (termasuk film) yang menawarkan paradoksalitas, kekacauan, dan dinamika perseturuan norma.

Jika karya adiluhung nampak menciptakan tembok pemisah antara karya yang baik dan buruk, dalam perspektif posmodern, justru meleburkan keduanya sehingga batas-batas adiluhung dengan populer menjadi kabur. Karya adiluhung bisa menjadi populer dan karya populer juga bisa menjadi adiluhung. Definisi menjadi adiluhung dan populer menjadi kabur dengan sendirinya. Hal ini dibuktikan, dilihat dari jumlah keuntungan yang diraup oleh karya -karya yang menampilkan paradoksalitas dan keterbalikan khas posmodern tersebut. Mereka semua mampu menorehkan penghasilan lebih dari \$200 juta dollar, jika dilihat dari jenis-nya, film-film animasi jenis ini marak diproduksi. Mengapa? Secara logika, jika produsen film animasi hanya memikirkan untung, yang mereka lihat tentu pasar-di mana masyarakat berada-yang menjadi sasaran mereka sehingga jika mereka memproduksi, mereka tentu memperhatikan apa yang diminta masyarakat. Satu film sukses, maka mereka akan memproduksi film dengan jenis yang sama dan pada akhirnya menjadi booming dan populer (Adi, 2011).

Jika manusia atau masyarakat dan karya dipersatukan, sebuah kata yang tepat yang mewakilinya adalah budaya. Budaya hampir berarti segalanya (Spradley, 1972: 6) sehingga di dalamnya terdapat manusia serta ciptaannya. Budaya populer sendiri mengacu pada kepercayaan, praktik-praktik, dan objek yang menyatu dalam kesatuan yang hidup dalam masyarakat yang semuanya diproduksi dari pusat-pusat komersil dan politik (Mukerji \& Schudson, 1991: 3). Ada unsur komersil di dalamnya sehingga populer-atau yang biasanya 
disingkat $p o p$ - tentu mengacu pada apa yang disukai masyarakat atau konsumen. Artinya, budaya pupuler merupakan studi mengenai bentuk dan sifat budaya yang perkembangannya masih menimbulkan pro dan kontra (Adi, 2011: 10-11).

Dapat dipersempit, jika dalam kajian posmodernisme yang dikaitkan dengan sastra populer, yang perlu diperhatikan adalah budaya dan masyarakat, sedangkan masalah sastra popular harus diperjelas dengan pemahaman tentang jenis sastra yang meliputi fiksi yang dapat berupa prosa dan film. Oleh karena itu, budaya populer dapat diterjemahkan dalam artian sastra populer (Adi, 2011: 19). Untuk mengkaji kaitan kedua istilah ini, perlu sebuah metode yang jelas. Berangkat dari teori posmodernisme, kemudian dihubungkan dengan pendekatan deterministik (dalam karya sastra populer). Bagaimana pendekatan deterministik dilakukan semata-mata dilihat dari pengertian seni yang bergantung pada dinamika sosial (masyarakat) atau psikologis sehingga itu berarti permintaan masyarakat yang pemikirannya sudah posmodern harus terpenuhi dan yang dapat memenuhi akan menjadi karya yang populer (Adi, 2011: 226227; Cawelti, 1976: 23). Jika ditilik dari nilai sastranya, pendekatan yang sangat mungkin dilakukan adalah pendekatan mimesis serta pragmatik karena hakikat dari isi karya posmodern yang populer adalah cerminan sosial serta permintaan masyarakat yang sepertinya bosan dengan karya yang monoton, yang pasti, dan biasa.

Pendekatan deterministik sebenarnya di- lakukan demi tercapainya sebuah jawaban mengenai kemunculan karya-karya posmodern yang tergolong nyeleneh. Kemajuan masyarakat, seperti yang sudah dikemukakan sebelumnya, mendorong para produsen untuk menghasilkan karya yang tidak melulu normal atau normatif, dalam artian karya yang hanya didominasi oleh kebenaran-kebenaran yang nampak pasti dan jelas. Mereka (masyarakat/ konsumen/pembaca) membutuhkan sesuatu yang-Lain atau hasrat deterministik khas masyarakat posmodern dari suatu sajian. Secara logika, perkembangan pikiran masyarakat selalu berkembang dan itu pasti memengaruhi selera mereka. Meski sastra populer hanya dianggap sebagai karya pelarian (escape literature), tetapi standar masyarakat untuk mendapat hiburan atau pelarian juga akan selalu berubah. Inilah yang memengaruhi para produsen untuk menghasilkan karya posmodern yang sesuai dengan pengetahuan masyarakat kontemporer. Terlebih, jika karya sastra adalah budaya, budaya itu akan mencirikan budaya orang yang mengonsumsinya (Gans, 1974: 11; Adi, 2011: 76).

Secara tersirat, jika produksi karya menuruti permintaan masyarakat, ini tak lain karena adanya hubungan atau kedekatan antara kenyataan dalam masyarakat-baik berupa ide, gagasan, realita, perasaan, dan sebagainya-dengan karya tersebut. Dengan kata lain, ini adalah sebuah peniruan atau bentuk mimesis dari realita sosial serta dorongan responsif antara penikmat karya dan produsen karya sehingga pendekatan mimesis dan pragmatik sebagai pendekatan sastra dapat dilakukan sebagai penunjang untuk menganalisis 
sastra populer. Seperti yang sudah ditekankan jika masyarakat mempunyai andil besar dalam terciptanya karya populer. Pembaca atau penonton dapat dilihat sebagai unsur pembentukan makna, barometer pembuatan fiksi populer, atau unsur yang mengganggu dampak dari fiksi populer (Adi, 2011: 171). Masalahnya, posmodern dengan segala atribut dekonstruktifnya serta sastra populer dengan segala refleksi viralnya, tak salah untuk menjembatani keduanya pada instrumen yang menjembatani konektivitas keduanya. Instrumen tersebut adalah realitas masyarakat siber yang pada akhirnya menunjang kedua poros kajian tersebut.

\section{Siber dan Internet: Virus Pop-Posmodern}

Karya sastra adalah bagian dari budaya dan sebagai produk budaya, sastra berlari searah dengan perkembangan kehidupan manusia, termasuk instrumen kehidupan manusia yang meliputi perkembangan media. Dari sekian media sastra, salah satu yang termutakhir adalah internet. Ia lahir sebagai media pengembangan informasi dan sains, tetapi yang pada gilirannya juga digunakan sebagai media mempromosikan karya sastra. Karya yang dinikmati melalui media internet dapat diklasifikasikan sebagai sastra dunia maya. Salah satu keunggulan dari genre teknis ini adalah ia dapat menawarkan interaksi pembaca-penulis yang tentunya sulit terjadi pada media konvensional. Dari mode interaksi ini, sastra siber hadir serta membombardir ke-adiluhung-an suatu karya. Sayembara, penghargaan, dan berbagai pola penganugerahan sastra adiluhung, pada akhirnya, akan jatuh pada bagaimana ia dihadapkan dengan proyeksi populisme. Karya adiluhung, misalnya Bumi Manusia, yang diekranisasi menjadi film setara posisinya dengan karya dari Wattpad (aplikasi di internet bagi pembaca dan penulis untuk menerbitkan cerita dalam berbagai genre, termasuk klasik, fiksi umum, fiksi sejarah, non-fiksi, puisi, fiksi penggemar, spiritual, humor, dan fiksi remaja).

Dalam laman internetnya, Gramedia mencatat beberapa film dari karya yang ditulis di Wattpad, seperti Matt and Mou (Wulanfadi), Sin: God Hates the Sin, Not the Sinner (Farandita), Invalidite: The Bridge of Perfection (Faradita), She's the Boss (Wiwi Suyanti), dan lain sebagainya. Karya-karya tersebut, telah dibaca oleh jutaan sampai puluhan juta pembaca. Belum lagi, media Twitter yang mampu menjadikan threads fiksi horor Mr. Simple, KKN di Desa Penari, menja di topik yang mengetren meskipun itu hanyalah potongan karya. Dari sini kita tahu bahwa terbatasnya dan sengitnya persaingan menuju panggung kesusastraan karena dikuasai oleh para elitis sastra dengan nilainilai keagungannya membuat strategi bergeser dari kompetisi menjadi kolaborasi. Kompetisi sastra menuntut berbagai modal bagi penulis dan kolaborasi media sosial menyediakan jalan bagi penulis yang minim modal. Baik karya adiluhung ataupun karya populer, keduanya juga difilmkan, tidak ada yang istimewa dari salah satunya, kecuali selera pasar. Dari sini, internet telah mengakomodasi dan memberi modal pada sastra sehingga istilah siber hadir. Siber sastra tentu menjadi jalan pintas dan ia hadir sebagai fenomena dekonstruktif dari wabah kesusastraan: legitimasi. 
Banyak istilah yang digunakan untuk mendefinisikan siber sastra seperti mesin sastra (Nelson, 1993), siberteks (Eskelinen, 2012), sastra digital (Hoover, et al. 2014), media digital (Ryan, 2013), dan sastra digital (Sanz, 2007). Sastra digital sangat dapat digeser menjadi istilah sastra elektronik. Sastra elektronik juga memiliki kedekatan dengan seni digital dan berbagai aplikasi yang dapat diprogram. Jika berkaitan dengan aplikasi, ada perusahaan di baliknya. Tentu saja, ada kepentingan komersial yang kuat dari perusahaan perangkat lunak, manufaktur komputer, dan penyedia peralatan lainnya yang terkait dengan media yang terprogram dan jaringan (Katherine, 2008). Media sosial berada pada wilayah ini.

Namun, menuduh perusahaan media tersebut juga merupakan kebencian hiperbolis karena institusionalisasi kesusastraan mana pun juga ada kepentingan komersialnya, mulai dari (menurut thebookpeople.co.uk) Specsavers National Book Awards, Nobel Prize in Literature, Booker Prize, Pulitzer Prize, Costa Book Award, Neustadt International Prize for Literature, Hugo Award, Guardian First Book Award, National Book Award, Bailey's Women's Prize for Fiction sampai level lokal seperti sayembara DKJ, Salihara, dan lain sebagainya. Semua penghargaan memiliki nominal penghargaan dan nominal tersebut menjelaskan bahwa ada sirkulasi pendanaan di baliknya. Tidak ada yang terjebak dalam sirkulasi kepentingan komersial. Bagaimana dengan HISKI (Himpunan Sarjana Kesusastraan Indonesia)? Sama saja, ada aspek komersil yang diperdagangkan untuk akses kesusastraan. Jadi, ini semacam permainan premium di suatu aplikasi, you pay, you play. Pengoposisian sastra populer yang hadir dengan uluran tangan internet merupakan ketersesatan sastra adiluhung atas eksklusivitasnya. Batas tersebut harus dikaburkan. Peniadaan batas ini adalah konsekuensi dekonstruktif dari budaya posmodern sehingga sastra kembali pada kondisi telanjangnya, tanpa institusi yang mewakilinya.

Kondisi telanjang sastra adalah tulisan. Sastra dari dunia maya juga merujuk pada definisi tersebut. Ia adalah teks-teks sastra tertulis, didistribusikan (diunggah) dan dibaca melalui layar telepon genggam, laptop, komputer, maupun perangkat elektronik lainnya. Pembentukan jaringan komputer, bersama dengan volatilitas informasi digital, memungkinkan dunia fiksi tumbuh, dimodifikasi dari dalam dan luar, untuk melahirkan dunia lain (Ryan, 2013).

Siber sastra lahir sebagai konsekuensi logis dari perkembangan teknologi. Botler dalam Writing Space: The Computer, Hypertext, and the History of Writing (1991) memprediksi bahwa lima abad berikutnya sistem buku akan didominasi buku elektronik yang akan membawa pada margin kultur literasi. Sistem cetak telah mendapat serangan serius dari garis keras para ekokritik sehingga bukan hal yang perlu ditertawakan kelak jika literasi dengan sistem cetak tidak lagi mendefinisikan penyajian pengetahuan. Pergeseran dari teks cetak ke teks elektronik merupakan konsekuensi dari pergeseran paradigma kebudayaan tradisional ke teknologi. Teks elektronik dibentuk oleh kesadaran pembaca sebagai penulis. Berbeda dengan teks cetak, ia satu arah, tunggal, dan 
tertutup. Komputer, seperti halnya semua teknologi lainnya yang mendekatkan pikiran dengan realitas, mendefinisikan bidang fisik dari pengalaman realitas dalam visualisasi pada layar datar sehingga kedekatan pembaca dengan penulis termediasi. Kolom comment, like, subscribe, follow dan lain sebagainya telah meleburkan batas konvensional yang selama ini memenjarakan pembaca dan penulis.

Jika sebelumnya sastra menggunakan koran dan majalah sebagai media, media siber sastra adalah internet. Dibandingkan dengan koran atau majalah sastra, siber sastra menjembatani penulis untuk menampilkan atau mengekspresikan karya mereka kepada pembaca. Pembebasan ini seakan menerjemahkan angan wacana bahwa setiap orang bisa menjadi penyair dan semua orang bisa menjadi kritikus sastra. Tentu saja, media elektronik menjadi sarana mengekspresikan diri bagi seseorang tanpa terjebak estetika politis tentang karya yang agung karena semua akan terjatuh pada karya yang dibaca dan memiliki pembacanya sendiri.

Secara historis, siber sastra sudah ada sejak akhir abad terakhir, yaitu sekitar 1990-an bersamaan dengan perkembangan teknologi. Tentu saja, kehadirannya juga menciptakan kontras. Di satu sisi, sambutan negatif terhadap siber sastra adalah anggapan bahwa siber sastra tidak mempertahankan kualitas, publikasi yang tidak memiliki kontrol, dan berbagai tudingan yang bermuara pada definisi sastra adiluhung. Di sisi lainnya, sambutan positif karena kehadiran siber sastra mempermudah akses penulis dan pembaca pada sastra. Interaktivitas pembaca-penulis pun terjadi.

Interaktivitas pembaca-penulis sendiri adalah bagian dari teori resepsi Hans Robert Jauss (1982). Jauss mempromosikan teori ini di Jerman ketika ia menerbitkan sebuah makalah yang berjudul Literary Theory as a Challenge to Literary Theory (1970). Teori resepsi berfokus pada respons pembaca. Penerimaan teks oleh pembaca adalah kunci kehadiran interaktivitas pembaca-penulis. Dalam proses interaktivitas ini, ada proses perendaman diri (selfimmersion) dan refleksi diri (self-reflection). Dua proses ini yang mampu dimediasi dengan baik oleh media digital. Media digital mampu merendam dan merefleksikan pembaca dalam dunia imajiner yang dirancang; fiksi dengan hiperteksnya menelusuri keliaran belantara makna, kode estetik puisi dengan mesin bahasanya mendorong kesadaran (Ryan, 2013). Media digital yang sudah menjadi gaya dan mode interaksi sosial dan psikologis akan membawa seseorang pada proses intensif yang mendorong pembaca menghasilkan teks (Fruin, 2013).

\section{Simpulan}

Kehadiran sastra melalui media elektronik seharusnya dapat diterima secara positif karena perkembangan teknologi yang menggeser pola konvensional akan mewabah dalam berbagai lingkup, termasuk sastra dan sastra akan menjadi bagian dari sejarah peradaban tersebut. Melalui media elektronik, diharapkan setidaknya untuk kedepannya akan memicu kehadiran dinamika dan potensi baru yang akan dilakukan oleh penulis. Gejala ini harus 
Poetika: Jurnal Ilmu Sastra

Vol. VII No. 2, Desember 2019

dilihat sebagai suatu inovasi, bukan ancaman legitimatif. Perkembangan teknologi seperti internet harus dilihat sebagai revolusi dalam kajian media dan sastra. Hal ini sekaligus memacu kreativitas dan strategi penulis karena penyebaran informasi melalui media internet sudah tidak terbendung. Karena pengaruh teknologi juga, budaya jejaring masif dan kompleks. Internet harus dilihat sebagai instrument yang memaksa inovasi dan membantu perkembangan sastra menjadi lebih baik (dalam artian sesuai peradaban zaman). Ruang bagi penulis untuk mengekspresikan dan mempromosikan karya mereka menjadi lebih fleksibel. Kekuasaan legitimasi kesusastraan tidak terletak pada institusi, tapi pada strategi adaptif pengarang.

Ambil contoh siber sastra di facebook. Kehadiran penulis senior yang aktif di facebook akan memberi pengaruh positif bagi penulis awam. Dari sebuah posting, kolom komentar, dan berbagai fitur menjadi jarring komunikasi yang bermanfaat. Bagi penulis awam, mereka akan mendapatkan arahan secara tidak langsung. Bagi penulis senior, mereka dapat mempromosikan karya sastra secara gratis. Komentar di media sosial mungkin adalah hal yang sepele, tetapi legitimasi dan modal sosial adalah hal yang bisa didapat. Itu adalah beberapa kelebihan siber sastra yang membuka interaktivitas pembaca-penulis yang sulit dilakukan dengan media konvensional (versi cetak).

\section{Daftar Pustaka}

Adi, Ida Rochani. 2011. Fiksi Populer: Teori \& Metode Kajian. Yogyakarta: Pustaka Pelajar.
DOI 10.22146/poetika.50779 ISSN 2338-5383 (print); 2503-4642 (online)

Bolter, J. D. 1991. Writing Space: The Computer, Hypertext and the History of Writing. Hillsdale, N. J.: Erlbaum.

Callinicos, Alex. 1989. Against Postmodernism: A Marxist Critique. Cambridge: Polity Press.

Cawelti, John G. 1976. Adventure, Mystery, and Romance: Formula Stories as Art and Popular Culture. Chicago: University of Chicago Press.

Descartes, Rene. 1998. Discourse on Method and Meditations on First Philosophy (edisi ke4, dialihbahasakan dalam bahasa Inggris oleh Donald. A. Cress). Indianapolis: Hackett Publishing Company.

Eskelinen, M. 2012. Cybertext Poetics: International Texts in Critical Media Aesthetics. New York: Continuum.

Fruin, N. W. 2013. Reading Digital Literature: Surface, Data, Interaction, and Expressive Processing. In Siemens, R. \& Schreibman, S. (Eds), A Companion to Digital Literary Studies. West Sussex. UK: Blackwell Publishing Ltd.

Gans, Herbert J. 1974. Popular Culture and High Culture: An Analysis and Evaluation of Taste. New York: Basic Books, Inc.

Hoover, D. L., Culpeper, J., \& O'Halloran, K. 2014. Digital Literary Studies: Corpus Approaches to Poetry, Prose, and Drama. New York: Routledge.

Jauss, H.R. 1982. Toward an Aesthetic of Reception. Minneapolis: University of Minnesota Press.

Lane, Richard J. 2000. Jean Baudrillard. New York: Routledge.

Lyotard, Jean-Francois. 1984. The Postmodern Condition: A Report on Knowledge. Mineapolis: University of Mineapolis Press.

Mukerji, Chandra \& Michael Schudson. 1991. Rethinking Popular Culture Contemporary Perspective in Cultural Studies. Barkeley \& Los Angeles Oxford: University of California Press.

Nelson, T. 1993. Literary Machines. Sausalitu, CA: Mindful press.

Osborne, Richard. 1991. Philosophy for Beginners. New York: Writers and Readers Publish- 
ing Inc.

Ryan, M. L. 2013. Fictional Worlds in the Digital Age. In Siemens, R. \& Schreibman, S. (Eds.), A Companion to Digital Literary Studies. West Sussex. UK: Blackwell Publishing Ltd.

Sanz, A., \& Romero, D. 2007. Literatures in the Digital Era: Theory and Praxis. Newcastle: Cambridge Scholars Publishing.
Sarup, Madan. 2011. Postrukturalisme \& Posmodernisme (dialihbahasakan dalam bahasa Indonesia oleh Medhy Aginta Hidayat). Yogyakarta: Jalasutra.

Spradley, James P. 1972. Culture and Cognition: Rule, Maps and Plans. San Fransisco: Chandler Publishing Co.

Sugiharto, Bambang. 1996. Postmodernisme: Tantangan Filsafat. Yogyakarta: Kanisius. 